\title{
FIRST REPORTED SAMPLES FROM THE RADIOCARBON LABORATORY OF THE UNIVERSITY OF TENNESSEE CENTER FOR ARCHAEOMETRY AND GEOCHRONOLOGY: DATES FROM THE MCCROSKY ISLAND ARCHAEOLOGICAL SITE (40SV43), SEVIER COUNTY, TENNESSEE, USA
}

\author{
Daniel C Weinand ${ }^{1,2} \bullet$ Richard R Polhemus $^{3} \bullet$ Sarah A Blankenship $^{1} \bullet$ Jan F Simek $^{1}$
}

\begin{abstract}
This study presents the results of archaeological samples submitted for dating at the recently constructed University of Tennessee Center for Archaeometry and Geochronology (UTCAG) radiocarbon dating laboratory (Knoxville, Tennessee, USA). The samples selected for this initial study were obtained from excavations at the McCrosky Island site (40SV43) in Sevier County, Tennessee, USA. Three of the samples dated were split between the UTCAG laboratory and another laboratory to assess the UTCAG laboratory protocols. In an effort to further validate the laboratory methods employed, several other samples were submitted without prior knowledge of contextual data. The dates obtained for these samples were then compared to their association with recovered artifacts and/or archaeological context.
\end{abstract}

\section{INTRODUCTION}

The University of Tennessee Center for Archaeometry and Geochronology (UTCAG) was established in 2001 with initial funding from the University of Tennessee President's Research Initiatives granting program. This award provided the necessary funding to implement the construction of a conventional radiocarbon dating laboratory through a partnership with researchers from the Illinois State Geological Survey (ISGS). Construction of the benzene extraction system, the creation and implementation of operation protocols for the laboratory, and a period of interlaboratory testing were completed in 2005.

The UTCAG laboratory currently utilizes the liquid scintillation counting (LSC) method for dating. Our laboratory is equipped with a benzene synthesis system and a Quantulus $1220^{\mathrm{TM}}$ ultra low-level scintillation counter. We are capable of processing a variety of samples, including charcoal, wood, bone, paleosol, coral, and shell. This facility serves as an additional resource for archaeologists and earth scientists throughout the United States.

In an effort to evaluate the laboratory's performance, a series of interlaboratory comparative samples were analyzed. These samples consisted of remaining portions of the Fourth International Radiocarbon Intercomparison (FIRI) data set, dendrochronologically dated wood samples, and intercomparisons of split samples dated at both ISGS and UTCAG. Once the results from these samples were deemed satisfactory, a blind test of archaeologically obtained samples was initiated to further examine the laboratory's performance. The results of this blind test are reported here.

A series of 15 dates were calculated from 14 archaeological samples obtained from eastern Tennessee, USA. Some of these samples consist of split samples sent to Beta Analytic, Inc. (Miami, Florida, USA). Other samples were obtained from features containing lithic and ceramic artifacts representative of known temporal contexts. These dates are presented as documentation of the efforts at the UTCAG dating laboratory, though periodic evaluations of accuracy are an ongoing component of the laboratory protocol.

\footnotetext{
${ }^{1}$ University of Tennessee, Department of Anthropology, 250 South Stadium Hall, Knoxville, Tennessee 37996-0720, USA.

${ }^{2}$ Corresponding author. Email: dweinand@utk.edu.

${ }^{3}$ Frank H. McClung Museum, 1327 Circle Park Drive, Knoxville, Tennessee 37996-3200, USA.
} 


\section{METHODS}

\section{Samples}

The samples selected for this study were obtained from archaeological investigations of the McCrosky Island site (40SV43), Sevier County, Tennessee $\left(35^{\circ} 55^{\prime} 48^{\prime \prime} \mathrm{N}, 83^{\circ} 36^{\prime} 1^{\prime \prime} \mathrm{W}\right)$ (Figure 1). Artifacts recovered from the site indicate that it was occupied from the Early Woodland to Late Mississippian periods, about 800 BC-AD 1600. Sample collection began in 1995 and currently continues (Polhemus 1996). A list of the sample types and year collected is presented in Table 1. Samples were dried before being sent for radiometric analysis at UTCAG or Beta Analytic, Inc.

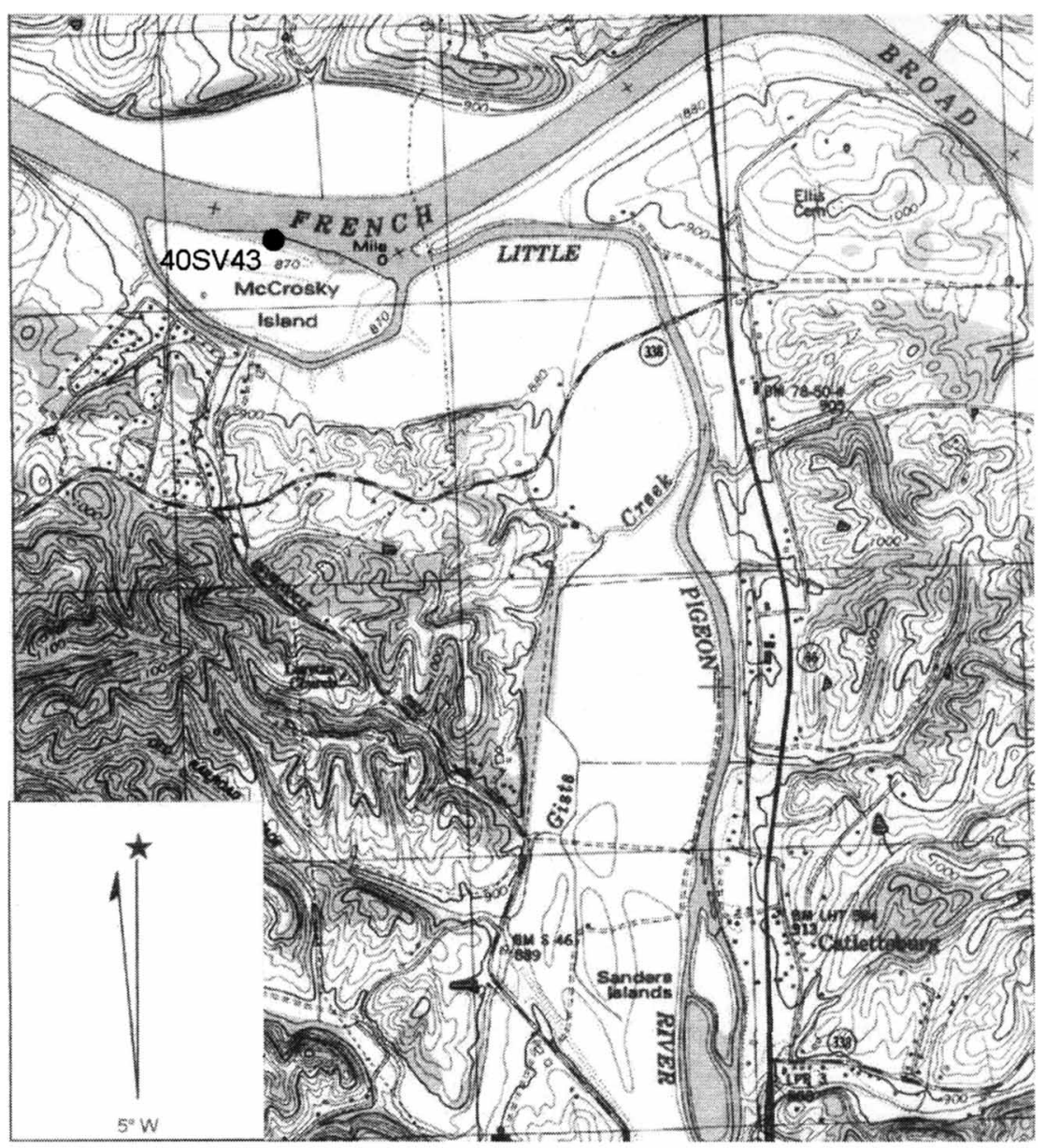

Figure 1 Location of the McCrosky Island archaeological site (40SV43); 1 inch equals 2000 feet.

\section{Sample Pretreatment}

Samples were rinsed with deionized water $\left(\mathrm{DI} \mathrm{H}_{2} \mathrm{O}\right)$ and were then inspected under an optical microscope for obvious contaminants such as grass, rootlets, and any other foreign materials. Samples were subsequently dried overnight in an $80^{\circ} \mathrm{C}$ oven. Chemical pretreatment of 4 of the samples dated consisted of the acid/alkali/acid (AAA) method (Table 1). Samples were boiled in $2 \mathrm{~N}$ hydrochloric acid $(\mathrm{HCl})$ for $1 \mathrm{hr}$ in order to remove inorganic carbon contaminants. Upon cooling and set- 
Table 1 Samples analyzed by UTCAG.

\begin{tabular}{llll}
\hline $\begin{array}{l}\text { Sample } \\
\text { identification }\end{array}$ & Sample description & $\begin{array}{l}\text { Year } \\
\text { collected }\end{array}$ & $\begin{array}{l}\text { UTCAG } \\
\text { pretreatment }\end{array}$ \\
\hline 40SV43C14-5 & Charcoal associated with pit feature & 2005 & Acid only \\
40SV43C14-6 & Charcoal from basin feature & 2000 & AAA \\
40SV43C14-7 & River cane & 1995 & AAA \\
40SV43C14-8 & Log associated with feature & 1995 & AAA \\
40SV43C14-9 & Log associated with pit feature & 1995 & AAA \\
40SV43C14-13 & Charred tree near riverbank & acid only \\
40SV43C14-17 & Charcoal associated with midden & 2005 & Acid \\
40SV43C14-18 & Charcoal associated with pit feature & 1995 & Acid only \\
40SV43C14-19 & Charcoal associated with pit feature & 1995 & Acid only \\
40SV43C14-20 & Charcoal from basin feature & 1995 & Acid only \\
40SV43C14-22 & Charcoal from basin feature & 1995 & Acid only \\
40SV43C14-23 & Charcoal from basin feature & 2006 & Acid only \\
40SV43C14-24 & Charcoal from basin feature & 2006 & Acid only \\
40SV43C14-25 & Charcoal from pit feature & 2006 & Acid only \\
\hline
\end{tabular}

${ }^{a}$ Indicates those samples split between UTCAG and Beta Analytic, Inc.

tling of the material, the samples were neutralized by rinsing with DI $\mathrm{H}_{2} \mathrm{O}$. Humic contaminants were removed by boiling the samples in $0.5 \mathrm{~N}$ sodium hydroxide $(\mathrm{NaOH})$ for $30 \mathrm{~min}$. Once cooled, the samples were rinsed several times with DI $\mathrm{H}_{2} \mathrm{O}$. The samples were then boiled twice with fresh DI $\mathrm{H}_{2} \mathrm{O}$ to expel final traces of $\mathrm{NaOH}$ absorbed by the material. After boiling, the samples were allowed to cool and again rinsed with DI $\mathrm{H}_{2} \mathrm{O}$. Samples were treated with $5 \%$ phosphoric acid $\left(\mathrm{H}_{3} \mathrm{PO}_{4}\right)$ for 20 min and subsequently rinsed with $\mathrm{DI} \mathrm{H}_{2} \mathrm{O}$ to neutrality. Finally, the samples were dried overnight in an $80^{\circ} \mathrm{C}$ oven.

The remaining 10 charcoal samples submitted for dating were found to be too friable for the standard AAA pretreatment process (see Table 1). Therefore, only the initial acid pretreatment was performed for these samples, followed by several $\mathrm{DI}_{2} \mathrm{O}$ rinses to return the samples to neutrality. The samples were then dried overnight in an $80^{\circ} \mathrm{C}$ oven.

\section{Benzene Synthesis}

Benzene synthesis involved 4 primary steps: 1) combustion; 2) lithium carbide formation; 3) acetylene generation; and 4) benzene trimerization. The procedures are based on those established and utilized by the ISGS laboratory (see Noakes et al. 1965, 1967; Coleman et al. 1972). Combustion consisted of a 3-part process. First, the material was combusted in an argon-rich atmosphere at $550^{\circ} \mathrm{C}$. This was followed by combustion in an argon-rich atmosphere at $750{ }^{\circ} \mathrm{C}$. Finally, samples were completely pyrolized in an oxygen-rich atmosphere at $750^{\circ} \mathrm{C}$. Benzene synthesis of the oxalic acid II standard was performed under these same conditions. Combustion temperature, however, was maintained at $450{ }^{\circ} \mathrm{C}$ for oxalic standard combustion. Throughout this process, gases were filtered through silver nitrate $\left(\mathrm{AgNO}_{3}\right)$ and chromic acid $\left(\mathrm{Na}_{2} \mathrm{Cr}_{2} \mathrm{O}_{7}\right)$ solutions for removal of residual chlorine (from $\mathrm{HCl}$ pretreatment) and sulfur dioxide $\left(\mathrm{SO}_{2}\right)$ (generated by oxidation of organic sulfur in samples during combustion), respectively. Excess water was removed by freezing in a trap cooled by a dry ice and isopropyl solution. The carbon dioxide $\left(\mathrm{CO}_{2}\right)$ obtained was collected in 3 liquid nitrogen traps. After reevacuation of the system, the $\mathrm{CO}_{2}$ was sublimated into precalibrated storage ball(s) and a measurement of the $\mathrm{CO}_{2}$ collected was obtained. 
To form lithium carbide $\left(\mathrm{Li}_{2} \mathrm{C}_{2}\right)$, lithium metal ( $2.5 \mathrm{~g}$ of lithium for each liter of sample $\mathrm{CO}_{2}$ ) was melted by heating to $615^{\circ} \mathrm{C}$ in a vacuum-evacuated reactor vessel. Once all of the lithium metal had melted and the excess gases evacuated, sample $\mathrm{CO}_{2}$ was introduced slowly, making sure that the reactor pressure did not exceed $-20^{\prime \prime} \mathrm{Hg}$. $\mathrm{CO}_{2}$ flow continued until the pressure in the reactor and storage ball(s) decreased to $-30^{\prime \prime} \mathrm{Hg}$ and the reactor temperature returned to $615^{\circ} \mathrm{C}$. The reactor temperature was then increased to $850^{\circ} \mathrm{C}$ in $30 \mathrm{~min}$ and maintained for an additional $45 \mathrm{~min}$ to convert any remaining carbon black to lithium carbide $\left(\mathrm{Li}_{2} \mathrm{C}_{2}\right)$. The reaction vessel was then evacuated until cooled to remove any remaining unreacted gases.

Acetylene was generated by introducing DI $\mathrm{H}_{2} \mathrm{O}$ to the cooled lithium carbide. Excess water was removed from the reaction gases with the aid of 2 traps, cooled with dry ice and isopropyl solutions. The acetylene was collected in 3 liquid nitrogen traps. All other non-condensable gases were evacuated from the system. Acetylene was then sublimated, passed through an additional dry ice/isopropyl trap to remove any remaining $\mathrm{H}_{2} \mathrm{O}$, and collected in the precalibrated storage ball(s).

Trimerization of benzene was achieved by introducing acetylene to a commercially available vanadium oxide catalyst (Coleman et al. 1972). A column containing preconditioned catalyst was activated under vacuum at $350{ }^{\circ} \mathrm{C}$ for $2 \mathrm{hr}$. The column was then allowed to cool to room temperature before the acetylene was introduced. The column was kept cool with an ice-water bath. Once trimerization was completed, the benzene was extracted by heating the column in a tube furnace at $120^{\circ} \mathrm{C}$ for $2 \mathrm{hr}$. The liquid benzene was frozen in a collection vial, cooled with a dry ice/isopropyl solution. The sublimated benzene was then prepared for the liquid scintillation counter.

All samples were counted in specially designed copper and Teflon ${ }^{\circledR}$ vials for use with the Quantulus 1220. A total sample volume of $5 \mathrm{~mL}$ was placed in the vial for counting. This consisted of $4 \mathrm{~mL}$ of sample, plus $1 \mathrm{~mL}$ of scintillation cocktail. In cases where sample volume was less than $4 \mathrm{~mL}$, an appropriate amount of dead benzene was added to achieve the $4 \mathrm{~mL}$ sample volume. Each sample was analyzed for $2700 \mathrm{~min}$, consisting of 27 cycles at $100 \mathrm{~min}$ each, in a prestandardized counting vial. Each sample was followed by a similar analysis of a background sample, counted in the same prestandardized counting vial.

\section{Analysis of ${ }^{13} \mathrm{C} /{ }^{12} \mathrm{C}$ Ratio}

The stable carbon isotopic composition of $\mathrm{CO}_{2}$ gas analyses were performed by the stable isotope laboratory of the Department of Earth and Planetary Science, University of Tennessee. Samples were analyzed using a Finnigan Delta ${ }^{\text {plus }}$ spectrometer. Results are reported relative to the Vienna Pee-Dee belemnite (VPDB) standard with a precision of $\pm 0.02 \%$.

\section{RESULTS AND DISCUSSION}

\section{Comparison with Beta Analytic, Inc.}

Three samples were split for analysis at UTCAG and Beta Analytic, Inc. (40SV43C14-5, 40SV43C14-13, 40SV43C14-23). The results from both laboratories are presented in Table 2 and indicate good agreement between splits of all 3 dated samples. The differences between samples 40SV43C $14-5$ and 40SV43C $14-13$ are within $1 \sigma\left(50{ }^{14} \mathrm{C}\right.$ yr and $55{ }^{14} \mathrm{C} \mathrm{yr}$, respectively), whereas sample 40 SV43C14-23 is within $2 \sigma\left(130{ }^{14} \mathrm{C} \mathrm{yr}\right)$. The dates for sample 40SV43C14-23 provide a chronological marker for Swift Creek Complicated Stamped ceramics (Jennings and Fairbanks 1939; Sears 1952) recovered from this archaeological context. 
Table 2 Results of interlaboratory comparison.

\begin{tabular}{lcl|cc}
\hline & \multicolumn{2}{c|}{ UTCAG } & \multicolumn{2}{c}{ Beta Analytic } \\
\cline { 2 - 5 } Sample identification & Conventional & $\delta^{13} \mathrm{C}$ & Conventional & $\delta^{13} \mathrm{C}$ \\
& age $(\mathrm{BP} \pm 1 \sigma)$ & $(\%)$ & age $(\mathrm{BP} \pm 1 \sigma)$ & $(\%)$ \\
\hline 40SV43C14-5 & $650 \pm 70$ & -25.27 & $600 \pm 40$ & -25.4 \\
40SV43C14-13 & $285 \pm 70$ & -26.75 & $230 \pm 40$ & -25.6 \\
40SV43C14-23 & $1640 \pm 70$ & -25.70 & $1510 \pm 40$ & -25.8 \\
\hline
\end{tabular}

An additional sample, 40SV23C14-17, was not submitted as a split sample, but was associated with an archaeologically contemporaneous midden feature sampled for dating by Beta Analytic (40SV23C14-15). The midden contained early Middle Woodland Connestee phase artifacts (see Ferguson 1971). The UTCAG sample dated to $1840 \pm 70 \mathrm{BP}$, and the Beta sample dated to $1760 \pm$ $40 \mathrm{BP}$. Although the difference between the conventional dates is $80{ }^{14} \mathrm{C}$ yr and falls within the 2- $\sigma$ range, the intercept of the $2-\sigma$ calibrated ages differs by only $10 \mathrm{yr}$ (cal AD 200 and cal AD 190, respectively). Therefore, it is concluded that the dates support the archaeologically identified contemporaneity. The dates are consistent with the Connestee phase in this region (Ferguson 1971).

\section{Contextual Analysis of Remaining Samples}

The reliability of the remaining dates was evaluated by comparison to their respective archaeological contexts, based on stratigraphic position or association with temporally known artifact types. The approximate temporal order of the remaining samples is presented in Table 3. The dates calculated by the UTCAG lab and a brief description of the samples are presented below.

Table 3 Approximate temporal order of remaining UTCAG samples.

\begin{tabular}{|c|c|c|c|}
\hline Time period & $\begin{array}{l}\text { Sample } \\
\text { identification }\end{array}$ & UTCAG \# & Sample description \\
\hline \multirow[t]{5}{*}{ Early Dallas phase } & 40SV43C14-18 & 07-005 & Charcoal associated with pit feature \\
\hline & 40SV43C14-9 & 06-024 & Log associated with pit feature \\
\hline & 40SV43C14-7 & $06-021$ & River cane \\
\hline & 40SV43C14-8 & 06-019 & Log associated with feature \\
\hline & 40SV43C $14-20$ & 07-007 & Charcoal from basin feature \\
\hline Emergent Mississippian & 40SV43C14-19 & 07-006 & Charcoal associated with pit feature \\
\hline Late Middle Woodland & 40SV43C14-6 & 06-020 & Charcoal from basin feature \\
\hline \multirow[t]{2}{*}{ Early Middle Woodland } & 40SV43C14-24 & 07-002 & Charcoal from basin feature \\
\hline & $40 \mathrm{SV} 43 \mathrm{C} 14-25$ & $07-003$ & Charcoal from pit feature \\
\hline Early Woodland & $40 \mathrm{SV} 43 \mathrm{C} 14-22$ & 07-009 & Charcoal from basin feature \\
\hline
\end{tabular}

UTCAG06-020. McCrosky Is., Fea. 201, 40SV43C14-6

$1400 \pm 70$

$\delta^{13} \mathrm{C}=-26.3 \%$ o

Charcoal from basin containing fire-cracked rock. Basin contains remains of late Middle Woodland period ceramics. Collected 2000 and submitted 2006 by R R Polhemus. This date is consistent with 2 other, stratigraphically contemporaneous features dated by Beta Analytic (Beta \#216648 and $\# 216649 ; 1300 \pm 40 \mathrm{BP}$ and $1280 \pm 40 \mathrm{BP}$, respectively). 
Comment: This sample provides a date for complicated stamped ceramics from this site that resemble Napier Complicated Stamped ceramics (Jennings and Fairbanks 1939; Sears 1952) but are not stylistically identical.

UTCAG06-021. McCrosky Is., Fea. 40, 40SV43C14-7 $875 \pm 70$ $\delta^{13} \mathrm{C}=-27.2 \%$

Carbonized river cane, associated with Early Dallas phase, Early Mississippian period burial feature. Collected 1995 and submitted 2006 by R R Polhemus. 40SV43C14-8 (UTCAG06-019) is associated with the same feature.

Comment: The date of this sample overlaps UTCAG06-019 at the 1- $\sigma$ level.

UTCAG06-019. McCrosky Is., Fea. 40, 40SV43C14-8

$$
\begin{array}{r}
770 \pm 70 \\
\delta^{13} \mathrm{C}=-27.9 \% \text { 。 }
\end{array}
$$

Carbonized wood, associated with Early Dallas phase, Early Mississippian period burial feature. Collected 1995 and submitted 2006 by R R Polhemus. 40SV43C14-7 (UTCAG06-021) is associated with the same feature.

Comment: The date of this sample overlaps UTCAG06-021 at the 1- $\sigma$ level.

UTCAG06-024. McCrosky Is., Fea. 158, 40SV43C14-9

$$
\begin{array}{r}
815 \pm 70 \\
\delta^{13} \mathrm{C}=-25.6 \% \text { o }
\end{array}
$$

Carbonized wood, associated with Early Dallas phase, Early Mississippian period rectangular pit feature. Collected 1995 and submitted 2006 by R R Polhemus. This feature is stratigraphically and artifactually related to features 40,76 , and 236 .

\section{UTCAG07-005. McCrosky Is., Fea. 76, 40SV43C14-18}

$$
\delta^{13} \mathrm{C}=\begin{array}{r}
730 \pm 70 \\
-24.8 \%
\end{array}
$$

Wood charcoal associated with Early Dallas phase, Early Mississippian period rectangular pit feature. Collected 1995 and submitted 2007 by R R Polhemus. This feature is stratigraphically and artifactually related to features 40,158 , and 236 .

UTCAG07-005V1. McCrosky Is., Fea. 76, 40SV43C14-18(2) $790 \pm 70$

$\delta^{13} \mathrm{C}=-24.8 \%$ o

This sample represents a second aliquot of the benzene extracted from UTCAG07-005. The sample was counted in a separately standardized sample vial and served as a test of the laboratory's vial standardization protocols. The difference in dates is $60{ }^{14} \mathrm{C} \mathrm{yr}$, within the $1-\sigma$ range.

UTCAG07-006. McCrosky Is., Fea. 120, 40SV43C14-19 $1155 \pm 70$ $\delta^{13} \mathrm{C}=-27.8 \%$ o

Mixed charcoal sample recovered from ash lens from cylindrical pit feature. Collected 1995 and submitted 2007 by R R Polhemus.

Comment: The date of this sample indicates an emergent Mississippian age for this feature and is consistent with the ceramic artifacts recovered from the feature. Feature 120 contained Mississippian vessel forms constructed of both shell and limestone tempered clays.

UTCAG07-007. McCrosky Is., Fea. 156, 40SV43C14-20

$$
\begin{array}{r}
915 \pm 70 \\
\delta^{13} \mathrm{C}=-26.5 \% \text { 。 }
\end{array}
$$

Mixed charcoal sample recovered from fire-cracked rock basin containing charred wood and maize remains. Collected 1995 and submitted 2007 by R R Polhemus. Maize was a dominant crop of Mississippian period peoples. 
Comment: This date places this pit feature in the Early Dallas phase, Early Mississippian period.

UTCAG07-009. McCrosky Is., Fea. 149, 40SV43C14-22

$2175 \pm 70$

$\delta^{13} \mathrm{C}=-\mathbf{2 6 . 9 \%}$

Mixed charcoal sample recovered from shallow circular basin feature. Collected 1995 and submitted 2007 by R R Polhemus. The feature contained artifacts and stone tools indicative of Early Woodland peoples of the Southeast USA. The date is consistent with these artifact types.

UTCAG07-002. McCrosky Is., Fea. 284, 40SV43C14-24

$1680 \pm 70$

$\delta^{13} \mathrm{C}=-27.6 \%$

Mixed charcoal sample recovered from fire-cracked rock-filled basin. Collected 2006 and submitted 2007 by R R Polhemus. This feature is from the same context as the features that provided samples 40SV43C14-17 and 40SV43C14-25.

Comment: The age of this sample is consistent with early Middle Woodland period artifacts recovered from this context.

UTCAG07-003. McCrosky Is., Fea. 287, 40SV43C14-25

$1100 \pm 70$

$\delta^{13} \mathrm{C}=-26.2 \%$

Mixed charcoal sample recovered from a cylindrical pit feature. Collected 2006 and submitted 2007 by $\mathrm{R} \mathrm{R}$ Polhemus. This feature is from the same context as features that provided samples 40SV43C14-17 and 40SV43C14-24. The age of this sample, however, is not consistent with early Middle Woodland period artifacts recovered from this context. Rather, this date indicates an early Mississippian period age for this feature.

Comment: Fine-scale analysis discovered the presence of small shell tempered ceramic sherds, indicating a Mississippian period intrusion into the feature.

\section{CONCLUSIONS}

The results obtained indicate that the sample pretreatment, benzene synthesis, counting vial standardization, and counting protocols adopted by the UTCAG ${ }^{14} \mathrm{C}$ laboratory are valid and produce comparably valid dating results. These conclusions are supported by the good agreement of the results of the 3 intercomparison samples and the good agreement between the dates and the identified archaeological contexts. The good agreement between the dates obtained for the 2 aliquots from 40SV43C 14-18 also demonstrates that the vial standardization protocol is satisfactory. Overall, the results indicate that the UTCAG ${ }^{14} \mathrm{C}$ laboratory is operational and producing reliable results. This will be further tested by our participation in the Fifth International Radiocarbon Intercomparison (VIRI).

\section{ACKNOWLEDGMENTS}

The authors would like to thank the ISGS and, particularly, Dr Jack Liu and Sallie Greenberg, for their assistance in setting up the UTCAG laboratory as well as their continued assistance during the subsequent testing period. Appreciation is also given to Sevierville Water Systems and the City of Sevierville, Tennessee, for providing funds in support of Dr Polhemus' archaeological investigation of the McCrosky Island site. Special thanks also to Drs Claudia Mora and Zheng-Hua Li of the UT Department of Earth and Planetary Science's stable isotope laboratory for providing the stable isotope measurements used in this study. The authors would also like to thank the University of Tennessee President's Research Initiatives program for providing funding for the UTCAG laboratory. Finally, this work is dedicated to the late Dr Michael J Elam, without whom this laboratory would not exist. 


\section{REFERENCES}

Coleman DD, Liu CL, Dickerson DR, Frost RR, Rafter TA. 1972. Improvement in trimerization of acetylene to benzene for radiocarbon dating with a commercially available vanadium oxide catalyst. In: Proceedings of the 8th International Conference on Radiocarbon Dating. Volume 1. Wellington: Royal Society of New Zealand. p B50-B62.

Ferguson LG 1971. South Appalachian Mississippian [PhD dissertation]. Chapel Hill: University of North Carolina. 279 p. Microfilm available from the University of North Carolina Photographic Service.

Jennings JD, Fairbanks CC. 1939. Type descriptions Swift Creek Complicated Stamp, Napier Complicated Stamp, Lamar Complicated Stamp, Mossy Oak Simple Stamp. Newsletter, Southeastern Archaeological Conference. Volumes 1 and 2. Lexington, Kentucky, USA.
Noakes JE, Kim SM, Stipp JJ. 1965. Chemical and counting advances in liquid scintillation radiocarbon dating. In: Proceedings of the 6th International Conference on Radiocarbon and Tritium Dating. Pullman, Washington, USA. Conf-650652. p 68-98.

Noakes JE, Kim S, Akers L. 1967. Recent improvement in benzene chemistry for radiocarbon dating. Geochimica et Cosmochimica Acta 31(6):1094-6.

Polhemus RR. 1996. Phase III archaeological survey and monitoring during construction of the McCrosky Island Wastewater Treatment Plant expansion, Sevier County, Tennessee. Report prepared for Jordan, Jones and Goulding and Sevierville Water Systems.

Sears WH. 1952. Ceramic development in the South Appalachian Province. American Antiquity 18(2):10110. 